\title{
A Scientometric Introspect of Literary Warrants Published in Annals of Library and Information Studies (ALIS) during the Last Decade
}

Manash Esh

University of North Bengal

Saptarshi LIS Ghosh ( $\square$ sghosh@nbu.ac.in )

University of North Bengal https://orcid.org/0000-0001-9567-5868

Research Article

Keywords: Scientometrics, Annals of Library and Information Studies, ALIS, CSIR, Document, keywords, Scopus

Posted Date: June 21st, 2021

DOI: https://doi.org/10.21203/rs.3.rs-619600/v1

License: (c) (i) This work is licensed under a Creative Commons Attribution 4.0 International License. Read Full License 


\section{Abstract}

Scientometric studies are enduring studies that portray an organized visual of messy data. The current study is a scientometric study based on secondary data sets included in Scopus. A corpus of 311 documents published in the journal Annals of Library and Information Studies (ALIS) from 2011 to 2020 was the population of the study. The study focused on several characteristics of the journal, including article distribution, average author per document, average document per year, authorship productivity, collaboration index, country-wise distribution of documents and citation analysis. The study retrieved the most prolific author contributing to this journal with 19 articles. The Council of Scientific and Industrial Research (CSIR) and the University of Delhi were the top literary contributors to the ALIS journal. The University of Kerala got the most citations per document (6.833). The maximum count of author keywords (Scientometrics) used in the journal from 2011 to 2020 was 135 .

\section{Introduction}

Research publications are the prime physical manifestations of intellectual thought contents conveyed in published literature, with the primary goal of transmitting innovative ideas or information to any specific field of knowledge to advance the subject or discipline.

As defined, 'Scientometrics' is the "quantitative methods of inquiry on the growth of science as an informational process." Ways of measuring research quality and impact, understanding the citation process, mapping specialized fields, and the use of indicators in research policy and management are only a few of the primary facets embodied in Scientometrics. This subject has traditionally focused on the observable or measurable components of communications.

The National Institute of Science Communication and Information Resources (NISCAIR), New Delhi, publishes ALIS, a renowned library science journal, on a quarterly basis. The journal's first editor was S.R. Ranganathan. The inaugural issue of Annals of Library Science was released in 1954. The scope of the journal is wider in sense that covers, articles, documentation notes and research reviews on library, documentation, and information science, as well as information systems, services, and products, information technology, information users, bibliometrics, Scientometrics and Informetrics, education and training, etc. (http://nopr.niscair.res.in/).

The reason for choosing ALIS was manifold. From its inception, this journal has been promoting the metric analysis in library and information science (LIS) domain with the contemporary threshold of other pragmatic approaches. The quality, editorial integrity as well as the peer reviewing process has been extraordinarily worth noting for this journal. Furthermore, after the rigorous academic audit enunciated by the UGC in 2016 regarding quality of publication, this journal kept its footprint quite stable in respect to originally and veracity of publications.

In this study, we collected and screened the literature published in ALIS from 2010-2020. Then, we used Citespace to conduct statistic computation of the information in the literature and further generated visual 
results with different node types such as keyword, country, author, and some others. Thus, this study aims to (i) the Annual growth of research publication and citation impact; (ii) analyse the prolific authors and the productive affiliation; (iii) find out the Country-wise Scientific productivity; (iv) to find out the cited documents; (v) to visualize relationship among references, authors, author's affiliations; and (vi) to determine the author keywords analysis of publications in ALIS.

\section{Review of literature}

1. Work on Scientometric study is numerous in count. As the coverage of the term is quite embracive, literature on this topic is widely scattered. A search made on 6th June 6, 2021, using Harzing's Publish or Perish tool (https://harzing.com/resources/publish or perish), retrieved the following result,

\begin{tabular}{|llllllll|}
\hline Query & Source & Papers & Citations & Years & Cites/Year & Cites/Paper & Cites/Author \\
\hline Scientometrics & Scopus & 200 & 18106 & 37 & 489.35 & 90.53 & 18106 \\
\hline
\end{tabular}

ALIS is a leading library science journal being published by the NISCAIR, New Delhi on quarterly basis. This journal publishes articles, documentation notes and research reviews on library, documentation and information science, information systems, services and products, information technology, information users, bibliometrics, Scientometrics and Informetrics, education and training and other related topics (www.niscair.res.in).

Literature on Bibliometric/Scientometric studies were available in various disciplines. In this article we grouped the existing literary warrants on six categories, i.e., "ALIS was the Focus", "Journal was the Focus", "Person was the Focus", "LIS Domain was the Focus", "Subject was the Focus" and "Database was the Focus". For each category pre-existing documents pertinent to this work was collected, screened, and critically evaluated for identification of its affinity towards the study.

ALIS was the Focus:

Bibliometric analysis of the journal ALIS during 2008 to 2018 was the latest study on ALIS which covered total number of 377 articles contributed by 723 authors published within 11 volumes and 44 issues. Apart from traditional bibliometric analysis this study calculated measures of authorship about the Degree of Collaboration (DC), Collaborative Index (Cl) and Collaborative Coefficient (CC) ${ }^{1}$. Degree of Collaboration(DC), Collaborative Coefficient(CC) for the period years (2007-2017) was observed as 0.65 in the other study which also measured the average publication of the journal and levels of multi-authored collaboration ${ }^{2}$. The growth of the LIS literature of 1985-90 and 2005-2010 (the period jump was not known) as reflected through ALIS was examined the year-wise growth of the library and information science literature, subjects covered during the specified periods, the most used form of literature, authorship pattern and most cited journals. The study revealed that INFORMATION AND COMMUNICATIONS TECHNOLOGY applications in LIS were gradually taking pace during the period 2005$2010^{3}$. URL related study of active and missing resource locators in the article published in ALIS during 
2006-2015 projected that 56.56 per cent of URLs are active and remaining 43.44 per cent of articles are missing. 'HTTP-404' is the common error code associated with missing URLs ${ }^{4}$. Bibliometric analysis of research published in ALIS, an India-based journal, for the period 2011-2017 compared this journal's trends with those of other LIS journals from the same geographical area (India, and Asia as a whole) and with the 10 highest-rated LIS journals worldwide using Scopus. The study highlighted that ALIS authors are focusing on metrics, bibliometrics and social networking, which follows global trends ${ }^{5}$. The reference accuracy of two prominent Indian LIS journals, viz. ALIS and DESIDOC Journal of Library and Information Technology reflected that a proper mechanism is needed in both the journals to maintain the quality of references in terms of errors ${ }^{6}$. Furthermore, the study on analysis of the number of articles published in Annals of Library and Information Studies (ALIS)and DESIDOC Journal of Library and Information Technology (DJLIT) during 2010-2013 identified immediacy index and impact factor of the two journals ${ }^{7}$. Significance of ALIS and its study was emphasized in a study in $2013^{8}$. The half-life of LIS journals and for book was studied and was 9 years and 14 years respectively ${ }^{9}$. The other study examined the number of articles published in ALIS and DJLIT between 2010 and 2013, as well as the number of citations received by these publications between 2010 and $2014^{10}$.

Journal was the Focus:

Many of the articles on bibliometrics focused and compared more than one LIS journals and their contribution to metric studies. From 2014 to 2018, a study explored the current trends in LIS publications in India. "Scientometric," and "ALIS," were mentioned in their publications, according to the study of cocitations; of reference sources or cited sources ${ }^{11}$. It was found that two-authored papers are predominant (48 per cent) in LIS publications and the collaborated articles of multi-authorships received greater average citations. Besides, in Indian LIS discipline, maximum collaboration occurs in intra-institutional level and inter-institutions within state level ${ }^{12}$. Methodological measures for identifying the top journals identified the seven journals as India's leading journals. These include ALIS, SRELS Journal of Information Management, DESIDOC Journal of Library \& Information Technology, Information Studies, COLLNET Journal of Scientometrics and Information Management, IASLIC Bulletin and Library Herald ${ }^{13}$. Pattern of measuring foreign authorship to three leading Indian LIS journals during 2008 to 2017 was examined and found that in last 10 year the three LIS journals publish total 186 foreign authored article having total 1267 citation and two-authored papers are predominant. Besides, the authors from Nigeria share maximum articles followed by USA ${ }^{14}$.

Person is the Focus:

Bibliometric works on individual persons were also observed during the last decade. A scientometric portrait of Bharat Ratna Amartya Sen, who is also a Nobel Laureate in Economic Sciences was done based on his writings between 1960 and 2015 that projected significant increase in the number of women in the workforce ${ }^{15}$. Other Studies focused on the prolific publishing career of India's Nobel Laureate poet Rabindranath Tagore $^{16}$ and V L Kalyane, one of the pioneers of bibliometric studies in India ${ }^{17}$. 
LIS Domain was the Focus:

Bibliometric analysis was carried out on Gujarat University's research papers published between 2004 and $\mathbf{2 0 1 3 ^ { 1 8 }}$. A Citation analysis on 8289 citations cited in 59 LIS doctoral theses submitted to Kuvempu University (15 theses) and University of Mysore (44 theses) has been carried out using Shodhganga etheses database. The study found that a total of 6883 journal citations were cited in 59 theses. The journal 'Scientometrics' has been cited 651 times and stands first in the rank list of journals. ALIS which is an Indian LIS journal stands in the third position in the rank list with 130 citations $^{19}$. A Study on Digital Library examined 681 Indian papers on research in digital libraries that were indexed in the Scopus database between $\mathbf{2 0 0 0}$ and $2009^{20}$. Publishing habits of academic members at three universities; University of Kerala, Mahatma Gandhi University, and University of Calicut was carried out and found that joint authorship is the mostly sought authorship pattern in these universities ${ }^{21}$. Using a set of bibliometric variables, study on India's success in RFID research was done in $2017^{22}$.

Subject is the Focus:

Bibliometric/Scientometric studies were carried out beyond the domain of LIS discipline too. Scientometric evaluation was investigated on the Jawaharlal Nehru Tropical Botanic Garden and Research Institute's publication productivity ${ }^{23}$. The number of papers published, the number of citations received, institutional collaborations, journal productivity, subject categories, and authorship pattern were all used to analyse the research contributions made by faculty members at the University of Pune's Department of Chemistry ${ }^{24}$. Academic publications published in Crystallography between 1989 and 2013, revealed the authorship pattern and research collaboration in the field ${ }^{25}$. Bibliometric analysis of contribution of Prof. G.N. Ramachandran's a noted biophysicist and crystallographer was carried out in $2010^{26}$. Scientometric analysis examined the publishing output of Indian Association for the Cultivation of Science scientists from 2008 to 2017, as recorded in the web of science database, to determine research performance, scholarly communication behaviour and citation effect ${ }^{27}$. Research output of life sciences faculty at Savitribai Phule Pune University in Maharashtra, India was measured in $2019^{28}$. Based on data on chronic liver disease research obtained from Scopus, a recent study focused on the pattern of literature growth, global publication shares and ranking, authorship pattern, collaborative coefficient, productivity and impact of most productive institutions and authors, sources and highly cited articles ${ }^{29}$. Bibliometric study on global autism literature that were indexed in the Scopus from 2001-2011 was made to look at publications in the subject including influential papers, journals, countries/territories, and authors ${ }^{30}$. For the years $\mathbf{2 0 0 0}$ to 2017, a scientometric analysis of global nuclear fuel research was conducted using a variety of scientometric indicators such as publication output, prolific authors, author collaboration networks, productive institutions involved, hot research subjects and citation pattern ${ }^{31}$. The collaborative elements of global solar cell research papers as indicated in Science Citation; Index-Expanded for the years 1991, 1995, 2000, 2005 and 2010 were investigated in the paper by B Dutta. ${ }^{32}$. Study on physics, and astronomy research contributions of Guru Nanak Dev University, Amritsar's from 2006 to 2015 was carried out in a recent study ${ }^{33}$. 
Database is the Focus:

Scientometric analysis carried out by Netaji Subhas Institute of Technology, Delhi staff and students during a twenty-year period (1996-2015) and indexed in the Scopus database ${ }^{34}$. The other scientometric analysis investigated Tumkur University Faculty's publishing output as reflected in the Scopus database over a 15-year period, from 2005 to $2019^{35}$. The current trends of LIS publications in India from 2014 to 2018 reviewed 1357 documents from 2014 to 2018 indexed in the Scopus database. The study found that majority of the 342 (25.2 per cent) papers published in the year 2018. The analysis of co-citations of reference sources or cited sources indicated that "Scientometric," and "ALIS" mentioned in their articles" A study used data from the Scopus database, which covered the years 1990 to 2017 and predicted global research in the field saw a rapid 18.46 per cent increase in publications ${ }^{37}$.

\section{Methodology}

The study retrieved and downloaded the global publication data on search string "Source title" ALIS from the Scopus database (http://www.scopus.com) covering the period 2011-2020. Other metrics, such as citation trends and collaboration patterns, were also collected and analysed. The three field plots; rfactorial analysis, country scientific production and dynamic word growth were made using the biblioshiny visualization tool.

\section{Results And Discussions}

\subsection{Growth and impact of research publications}

The impact of research publication can be measured with the citation received for a research paper. We gathered year-wise publication, mean citation per year per document (total 311) and mean citation per year. It is observed that the growth of research publications is in continuum and is increasing steadily over the years. We noted that a highest number 45 documents were published during the year of 2014. In 2011, the highest mean citation per document, mean citation per year and mean citation per year per document were $6.7777,6.7777$ and 0.6162 , respectively. 
Table 1

Average Citations

\begin{tabular}{|lllll|}
\hline Year & $\mathbf{N}$ & MCD MCY & MCYD \\
\hline 2011 & 36 & 6.7777 & 0.6777 & 0.6162 \\
\hline 2012 & 29 & 4.8620 & 0.5402 & 0.4862 \\
\hline 2013 & 27 & 4.6666 & 0.5833 & 0.5185 \\
\hline 2014 & 45 & 4.8444 & 0.6920 & 0.6056 \\
\hline 2015 & 38 & 2.3157 & 0.3859 & 0.3308 \\
\hline 2016 & 32 & 2.7187 & 0.5437 & 0.4531 \\
\hline 2017 & 32 & 2.5 & 0.625 & 0.5 \\
\hline 2018 & 28 & 1.6785 & 0.5595 & 0.4196 \\
\hline 2019 & 17 & 1.2352 & 0.6176 & 0.4118 \\
\hline 2020 & 27 & 0.5555 & 0.5555 & 0.2778 \\
\hline $\begin{array}{l}\text { Abbreviation: N = Number of documents; MCD = Mean Citation per document; MCY = Mean Citation per } \\
\text { year; MCYD = Mean Citations per year per Documents }\end{array}$ & \\
\hline
\end{tabular}

\subsection{Publication growth}

Table 2 shows the overall authorship pattern. Out of a total of 591 authors, there were 75 single-authored documents, 340 multi-authored documents. Here we witnessed that in 2016, the highest number of coauthors per document was 2.06. It showed a real picture of mean author per document (APD) and productivity per author in the stipulated timespan. The APD and productivity per author by we calculated using the formula as follows.

APD $=$ Number of authors/ Number of documents

Document per author $=$ Number of papers $/$ Number of authors

Here we found minimum APD as 1.55, with maximum document per author is 0.644 in the year 2015. On the other hand, we got maximum APD at 1.88 with minimum productivity per author at 0.531 in the year 2019.

$\mathrm{Cl}$ of documents is a mean number of authors per joint paper. To determine the mean number of authors per jointly authored paper, the following formula was used $\mathrm{Cl}=$ Total number of authors/ Total joint papers It can be observed from Table 2 that there was maximum $\mathrm{Cl} 2.41$ in the year 2011 and minimum $\mathrm{Cl} 1.9$ in the years 2020. 
Table 2

Publication growth

\begin{tabular}{|llllllll|}
\hline Year & N & SA & MA & DPA & APD & CAPD & Cl \\
\hline 2011 & 36 & 14 & 53 & 0.537 & 1.86 & 1.92 & 2.41 \\
\hline 2012 & 29 & 13 & 34 & 0.617 & 1.62 & 1.76 & 2.12 \\
\hline 2013 & 27 & 10 & 40 & 0.54 & 1.85 & 2 & 2.35 \\
\hline 2014 & 45 & 14 & 64 & 0.577 & 1.73 & 1.91 & 2.06 \\
\hline 2015 & 38 & 17 & 42 & 0.644 & 1.55 & 1.76 & 2.1 \\
\hline 2016 & 32 & 7 & 50 & 0.561 & 1.78 & 2.06 & 2.08 \\
\hline 2017 & 32 & 9 & 51 & 0.533 & 1.88 & 1.91 & 2.22 \\
\hline 2018 & 28 & 6 & 44 & 0.56 & 1.79 & 1.93 & 2.2 \\
\hline 2019 & 17 & 6 & 26 & 0.531 & 1.88 & 1.88 & 2.36 \\
\hline 2020 & 27 & 6 & 39 & 0.6 & 1.67 & 1.89 & 1.9 \\
\hline
\end{tabular}

311

Abbreviation: $\mathrm{N}=$ Number of documents; $\mathrm{SA}=$ Single Author; $\mathrm{MA}=$ Multiple Authors; $\mathrm{DPA}=$ Documents per Author; APD = Authors per Document; $\mathrm{CAPD}=$ Co-Authors per Documents; $\mathrm{Cl}=$ Collaboration Index

\subsection{Productive authors}

Table 3 lists the seven most productive authors, each of whom produced at least five papers in the journal during 2011-2020, as well as their citations, h-index, and title of the article with citation counts. The top seven most productive authors generated 66 documents in total, accounting for 21.29 per cent of the total number of publications. B.K. Sen was the most prolific author, contributing 19 papers, while S.M Pujar had the highest number of citations and citations per document in the table, with 58 and 8.22 , respectively. During the research period, Pujar's article "MOOCs and LIS education: A massive opportunity or challenge" published in March 2014 was the most cited among the top contributing authors in the ALIS journal. B.K. Sen followed up in his article title "Plant Genetics \& Breeding Research: Scientometric Profile of selected countries with special reference to India," with 14 citations. 
Table 3

-Topmost contributed authors

\begin{tabular}{|c|c|c|c|c|c|}
\hline Author & TP & TC & HI & HD & Citation \\
\hline $\begin{array}{l}\text { Sen, } \\
\text { B.K. }\end{array}$ & 19 & 37 & 4 & Top Indian LIS Journals; Sep-2014 & 8 \\
\hline $\begin{array}{l}\text { Garg, } \\
\text { K.C. }\end{array}$ & 11 & 53 & 4 & $\begin{array}{l}\text { Plant Genetics \& breeding research: Scientometric Profile of } \\
\text { selected countries with special reference to India; Jun- } 2011\end{array}$ & 14 \\
\hline $\begin{array}{l}\text { Dutta, } \\
\text { B. }\end{array}$ & 9 & 11 & 2 & One hundred years of Indian LIS periodicals; Sep-2014 & 3 \\
\hline $\begin{array}{l}\text { Gupta, } \\
\text { B.M. }\end{array}$ & 8 & 48 & 5 & $\begin{array}{l}\text { Dementia research in India: A Scientometric analysis of } \\
\text { research output during 2002-11 }\end{array}$ & 11 \\
\hline $\begin{array}{l}\text { Pujar, } \\
\text { S.M. }\end{array}$ & 7 & 58 & 5 & $\begin{array}{l}\text { MOOCS and LIS education: A massive opportunity or } \\
\text { challenge; March-2014 }\end{array}$ & 15 \\
\hline Ray, P.P. & 6 & 8 & 2 & $\begin{array}{l}\text { Publications of Rabindranath Tagore: A bibliometric study; } \\
\text { Sep-2015 }\end{array}$ & 2 \\
\hline $\begin{array}{l}\text { Tripathi, } \\
\text { H.K. }\end{array}$ & 6 & 31 & 4 & $\begin{array}{l}\text { Scientometrics of Indian Crop Science research as reflected } \\
\text { by the coverage in Scopus, CABI and ISA database during } \\
2008-2010\end{array}$ & 12 \\
\hline
\end{tabular}

\subsection{Most cited documents}

Table 4 shows the top cited papers based on the number of citations they received. These most cited documents were published between 2011 and 2020, according to our research. B.K. Sen and B. Dutta's articles received the highest local citation (LC) value of four, and publication by B. Dutta "A quantitative assessment of the articles on environmental issues published in English-language Indian dailies" received the highest global citation (GC) value of 14, while S.M. Pujar and R Mittal works got the most exceptional attention from the scholarly community with 14 global citations. 
High Cited documents, having a more significant influence

\section{Title}

Author

Year

\section{LC GC LC/GC \\ Ratio \\ (per \\ cent)}

Female Graduate of British Empire - Kadambini Ganguly

A quantitative assessment of the articles on environmental issues published in English-language Indian dailies

$\begin{array}{lllll}\text { SEN B.K (BK) } \quad 2014 & 4 & 8 & 50\end{array}$

MOOCs and LIS education: A massive opportunity or challenge

Application of Bradford's law on journal citations: A SINGH KP study of Ph.D. theses in social sciences of University of Delhi

A study of citation accuracy in psychology theses submitted to the University of Mysore

One hundred years of Indian LIS periodicals Growth and visibility of LIS journals: an analytical study

A bibliometric analysis of publications of the Chemistry Department, University of Pune, India, $1999-2012$

Citation generation potential

Adoption of social media by online newspapers of Kashmir

Impact of online interactivity dimensions on library website quality

Scientometric analysis of Pakistan's S\&T research output

Role of consortia in preservation of e-journals

Bradford's zones and productivity of journals in psychology doctoral theses

Medicinal and Aromatic Plants Abstracts: a system migration experience

E-resources usage and research productivity

An empirical assessment of information literacy competency of social science researchers: a gender perspective
DUTT B

$2013 \quad 4 \quad 14$

$2014 \quad 3 \quad 14$

21.43 $2014 \quad 3 \quad 11$

27.27

PUJAR S.M.

$2014-3-11$

28.57

$\begin{array}{lllll}\text { HARINARAYANA } & 2011 & 3 & 4 & 75\end{array}$
NS

$\begin{array}{lllll}\text { DUTTA B } & 2014 & 2 & 3 & 66.67 \\ \text { SINGH J } & 2014 & 2 & 7 & 28.57\end{array}$

$\begin{array}{lllll}\text { NAGARKAR S } & 2014 & 2 & 7 & 28.57\end{array}$

$\begin{array}{lllll}\text { SEN BK } & 2013 & 2 & 2 & 100 \\ \text { GUL S } & 2013 & 2 & 7 & 28.57\end{array}$

DE SARKAR T

$\begin{array}{llll}2012 & 2 & 6 & 33.33\end{array}$

GUPTA BM

$\begin{array}{lll}2012 & 2 & 11\end{array}$

18.18

GAUR RC

$\begin{array}{llll}2012 & 2 & 6 & 33.33\end{array}$

$\begin{array}{lllll}\text { ZAFRUNNISHA } & 2012 & 2 & 4 & 50\end{array}$ $\mathrm{N}$

MITTAL R

$\begin{array}{llll}2011 & 2 & 14 & 14.29\end{array}$

PRATHAP G

$\begin{array}{llll}2011 & 2 & 10 & 20\end{array}$

SINGH R

$\begin{array}{llll}2020 & 1 & 2 & 50\end{array}$


Title

Author

Year

LC GC

LC/GC

Ratio

(per

cent)

Abbreviation: $L C=$ Local Citations; $G C=$ Global Citations

\subsection{Top 10 leading Institutions contributing maximum research.}

Table 6 lists the top 10 most relevant affiliations from which ALIS journal research has been conducted (2011-2020). It was discovered that the CSIR and the University of Delhi were the leading institutions in terms of the number of documents and the citation count; however, the University of Kerala topped the list in terms of citation per document (CPD), with 6.8333 , followed by the CSIR with 5.3333 CPD.

Table 6

most leading Affiliations and publications and citations

\begin{tabular}{|llll|}
\hline Affiliations & Document & Citation & CPD \\
\hline CSIR-NATIONAL INSTITUTE OF SCIENCE & 24 & 128 & 5.3333 \\
\hline UNIVERSITY OF DELHI & 22 & 50 & 2.2727 \\
\hline JAWAHARLAL NEHRU UNIVERSITY & 10 & 25 & 2.5 \\
\hline UNIVERSITY OF MYSORE & 9 & 40 & 4.4444 \\
\hline UNIVERSITY OF CALCUTTA & 9 & 8 & 0.8888 \\
\hline UNIVERSITY OF COLOMBO & 9 & 37 & 4.1111 \\
\hline UNIVERSITY OF DHAKA & 9 & 28 & 3.1111 \\
\hline INDIAN NATIONAL SCIENCE ACADEMY & 9 & 26 & 2.8888 \\
\hline VIDYASAGAR UNIVERSITY & 8 & 9 & 1.125 \\
\hline UNIVERSITY OF KERALA & 6 & 41 & 6.8333 \\
\hline Abbreviation: CPD = Citation per document & & \\
\hline
\end{tabular}

\subsection{Scientific output by countries}

Figure 1 depicts scientific output by countries. The map was generated through "Biblioshiny," which provides multiple shades representing three colors, namely, blue for different productivity rates, dark blue for high production, and grey for no documents. The most productive countries relating to published documents from the journal "ALIS" Processing (2011-2020) were India (234 documents, 75.24 per cent), followed by Nigeria ( 23 documents, 7.39 per cent), and Sri Lanka (13 documents, $4.18 \%$ ). In contrast, the highest number of citations was attributed by the India 767 with mean citations per article of 3.28 
followed by and Sri Lanka (40, with a mean citations per article of 3.07 and Nigeria (62 with a mean citations per article of 2.69).

\subsection{Factorial analysis based on author's keywords.}

The factorial analysis is a graphical depiction of word collections tied to a given parameter. Author keywords for publications published in ALIS(s) from 2011 to 2020 was indexed in Scopus. Based on the keywords, the following parameters were examined. Figure 2 depicts the investigation of the dynamics of the time-dependent occurrences of the author's keywords. The frequency of all main terms as cumulated, occurrences increased over time, although a few got exponent more rapidly than others. The terms that got highest incremental count in frequency throughout the time were 'Scientometrics', 'Bibliometrics', 'India', 'Information Literacy', 'Nigeria', 'Citation analysis,' 'E-resources', 'LIS Journals', 'Open access' and 'Academic libraries'. The dynamic word growth continued to develop from 2011 and maintained the status quo. The broad terms emphasized in the figure had 11 keywords, including Scientometrics (135 frequency), India and Bibliometric (129 and 115 frequencies), and Nigeria and 'E-resources' (70 and 65 frequencies) respectively.

\subsection{Conceptual Structure Map-method: Multiple Correspondence Analysis (MCA) of high-frequency titles}

We also delved into Cluster analysis and MCA of titles with a high frequency of occurrence. MCA was performed on the titles in the data set from 2011 to 2020. Figure 3 depicts the conceptual structure of the keywords connected with the titles considered in this study. It compresses 57 keywords with various factors into a low-dimensional space to generate an intuitive two-dimensional (or three-dimensional) graph that uses plane distance to show title similarity. The results are interpreted based on the relative placements of the points and their distribution along the dimensions; the closer words are depicted in the map, the more similar their distribution is. Cluster 1 (red colour) consists of 48 keywords that Focus on documents related to information, study, library, India, university and libraries, science, journals, resources, assessment, LIS and so on, whereas Cluster 2 (blue colour) consists of nine keywords that Focus on documents related to research, analysis, scientometric, bibliometric, output, publications, global, productivity, scientometric and so on.

\section{Three-fields plot relations among References, Top Authors, Top Affiliations}

Three-fields plot relations between 20 (Authors-AFRICAN UNION, References-CR, Affiliations-AU_UN) A multi-field plot among authors, references, and author's affiliations in the top 20 rankings. Figure 4 depicts, author B.K. Sen had incoming flow from two references and outgoing flow to three author's affiliations, with the reference "K.C. Garg, P. Pandhi, A study of collaboration in user science and technology (2014)" having outgoing flow to five authors, all of whom were interconnected, and the CSIR affiliation is linked to five authors in the figure. Besides, some references have none to a minimal relationship with the 
affiliations and authors. This conveys active collaboration among various authors and collaboration structure within several references and affiliations.

\section{Conclusion}

In the present study, we analysed the growth and publication trends of ALIS journal. The journal has gone tremendous change in terms of both quantities as well quality. There are many visibilities and impact of the research work it has published during the last 10 years. Overall, 963 citations were found from 311 documents. The annual growth of the published documents was observable from the analysis. Sen, bk contributed the highest number of research documents (19) and ranked as the most active author in this journal. During the study period, the maximum mean CPD and mean citation per year were 6.77 and 6.77, respectively and the mean CPD per year was 0.6162 , respectively, where co-authors per document was 2.06 (maximum) in 2016 and when mean APD was 1.5, document per author was maximum 0.644 in 2015. In the year 2019, we had the highest author pr document of 1.88 and the lowest productivity per author of 0.531. In 2011, the cumulative index was at its highest (2.44) and lowest (1.9) in 2020. The papers of Prof. B.K. Sen and Dr. B. Dutta gained maximum local citations, whereas Pujara S.M and Mittal R's work received 14 global citations. The CSIR and the University of Delhi were the top contributors of documents to the ALIS journals. In terms of citations per document, the University of Kerala came out on top (6.833). India contributed 75.24 per cent of documents in the journal, followed by Nigeria (7.39 per cent). Every year, it has been seen that the expansion of dynamic words growth continues. During the period 2011-2020, the utmost number of author keywords (Scientometrics) utilized in the journal was 135 words.

\section{References}

Abu, K. S., \& Verma, S. (2019). Authorship trends and collaborative patterns on annals of library and information studies. Library Philosophy and Practice, 2019(April).

Aswathy, S., \& Gopikuttan, A. (2013). Productivity pattern of universities in Kerala: A scientometric analysis. Annals of Library and Information Studies, 60(3), 176-185.

Choudhary, P. K., Choudhary, P. K., \& Engineering, C. (2016). Published output of netaji subhas institute of technology , DELHI ( 1996-2015): A SCIENTOMETRIC. 52, 1-7.

Deshmukh, P. P. (2011). Citations in annals of library and information studies during 1997 to 2010: A study. Annals of Library and Information Studies, 58(4), 355-361. 
Devi, B. M., \& Lekshmi, V. (2014). Scientometric Assessment of Publication Productivity of JNTBGRI, Thiruvananthapuram. 34(2), 147-151.

Dutt, B., \& Nikam, K. (2015). A scientometric overview of collaboration pattern in global solar cell research. 62(September), 157-167.

Garg, K. C., \& Bebi. (2014). A citation study of Annals of Library and Information Studies (ALIS) and DESIDOC Journal of Library and Information Technology (DJLIT). Annals of Library and Information Studies, 61(3), 212-216.

Gupta, B. M., Dhawan, S. M., \& Kolle, S. R. (2019). Global Research Studies on “ Electronic Journals " during 1990-2017 : A Scientometric Study. 39(3), 116-124.

Gupta, V. K. (2017). Accuracy of references in two Indian library and information science Journals. Annals of Library and Information Studies, 64(3), 181-189.

Jeyshankar, R., \& Vellaichamy, A. (2016). Scientometric Analysis of Autism Research Output during 20072011. SRELS Journal of Information Management, 53(1).

https://doi.org/10.17821/srels/2016/v53i1/86768

Kalaiappan, V., Kaliyaperumal, K., \& Rajasekar, V. (2010). Scientometric Analysis of Literature Output of Prof . G . N . Ramachandran in the Subjects of Biophysics and Crystallography. 30(6), 3-11.

Khanna, S., Singh, N. K., Tewari, D., \& Saini, H. S. (2017). Scientometric Analysis of the Research Output of Physics and Astronomy of Guru Nanak Dev University during 2006-15. 37(5), 337-345.

Koley, S., \& Sen, B. K. (2016). Biobibliometric portrait of V L Kalyane, a stellar biobibliometrician. Annals of Library and Information Studies, 63(3), 161-175. 
Kumar, A., Gupta, R., \& Gupta, B. M. (2016). A Scientometric Assessment of Global Publication Output on RFID with Reference to India During 2006-15. 36(4), 205-211. https://doi.org/10.14429/djlit.36.4.9742

Kumar, D. V., \& Sangeetha, M. (2019). Citations analysis of LIS theses submitted to Kuvempu University and University of Mysore. Library Philosophy and Practice, 2019.

Kumar, H. A., Dora, M., \& Desai, A. (2015). A Bibliometrics Profile of Gujarat University , Ahmedabad during 2004-2013. 35(1), 9-16. https://doi.org/10.14429/djlit.35.1.7699

Mamatha, M. (2020). SCIENTOMETRIC ANALYSIS OF PUBLICATION OUTPUT OF TUMKUR UNIVERSITY FACULTY : A STUDY BASED ON SCOPUS DATABASE. 56(4).

Mondal, D., Chakrabarti, B., \& Maity, A. (2019). Publications Output of the Indian Association for the Cultivation of Science during 2008-2017 : A Scientometric Assessment. 39(5), 244-250.

Mondal, D., \& Jana, S. (2018). Collaborative authorship trend in leading Indian LIS journals. DESIDOC Journal of Library and Information Technology, 38(5), 320-325. https://doi.org/10.14429/djlit.38.5.12917

Mondal, D., \& Maity, A. (2019). Foreign authorship pattern in selected library and information science journals of India. DESIDOC Journal of Library and Information Technology, 39(1), 17-22. https://doi.org/10.14429/djlit.39.1.13691

Nagarkar, S. (2014). A bibliometric analysis of publications of the Chemistry Department, University of Pune, India, 1999-2012. Annals of Library and Information Studies, 61(2), 85-92.

Nagarkar, S., Veer, C., \& Kumbhar, R. (2015). Bibliometric analysis of papers published by faculty of life science departments of Savitribai Phule Pune University during 1999-2013. DESIDOC Journal of Library and Information Technology, 35(5), 368-375. https://doi.org/10.14429/djlit.35.5.8429 
Naheem, K. T., Nagalingam, U., \& Ramesha, B. (2017). Chronic liver disease (Cld) research in saarc countries: A scientometric analysis of research output during 1996-2015. Annals of Library and Information Studies, 64(1), 59-68.

Nath, A., \& Jana, S. (2020). Bibliometric Analysis of Annals of Library and Information Studies (ALIS). Library Philosophy and Practice, 2020(January).

Neelamma, G. (2018). AUTHORSHIP PATTERN AND COLLABORATIVE MEASURES IN THE FIELD OF CRYSTALLOGRAPHY. (November).

Pandita, R. (2013). Annals of library and information studies (ALIS) journal: A bibliometric study (20022012). DESIDOC Journal of Library and Information Technology, 33(6), 493-497. https://doi.org/10.14429/djlit.33.5481

Prieto-Gutiérrez, J. J., \& Segado-Boj, F. (2019). Annals of Library and Information Studies: A Bibliometric Analysis of the Journal and a Comparison with the Top Library and Information Studies Journals in Asia and Worldwide (2011-2017). Serials Librarian, 77(1-2), 38-48.

https://doi.org/10.1080/0361526X.2019.1637387

Qadri, S., \& Shukla, A. (2020). Growth of Indian library and information science literature: A study of annals of library and information studies. Annals of Library and Information Studies, 67(4), 209-214.

Rattan, G. K. (2013). Acknowledgement patterns in annals of library and information studies 1999-2012. Library Philosophy and Practice, 2013, 1-11.

Ray, P. P., \& Sen, B. K. (2015). Publications of Rabindranath Tagore: A bibliometric study. Annals of Library and Information Studies, 62(3), 177-185. 
Sahu, R. R., \& Parabhoi, L. (2020). Bibliometric Study of Library and Information Science Journal Articles during 2014-2018: LIS Research Trends in India. 4O(6), 390-395.

Sahu, R. R., \& Parabhoi, L. (2020). Bibliometric study of library and information science journal articles during 2014-2018: Lis research trends in India. DESIDOC Journal of Library and Information Technology, 40(6), 390-395. https://doi.org/10.14429/djlit.40.6.15631

Sen, B. K. (2014). Top 7 Indian LIS journals. Annals of Library and Information Studies, 61(3), 253-256.

Sinha, A. K. (2017). Scientometric study of books authored by nobel laureate amartya sen. Annals of Library and Information Studies, 64(1), 9-15.

Sudarsana, D., \& Baba, M. S. (2019). Global nuclear fuel research during 2000 to 2017 : A scientometric analysis. 66(September), 85-93.

Vinay Kumar, D., \& Sushmitha, M. (2019). Recovery of missing URLs cited in annals of library and information studies: A study of time travel. Annals of Library and Information Studies, 66(1), 24-32.

Visakhi, p., \& kumbar, b. D. (2020). Research on digital libraries : a scientometric assessment of india 's publications during 2000-19. 56(2), 62-74.

\section{Figures}




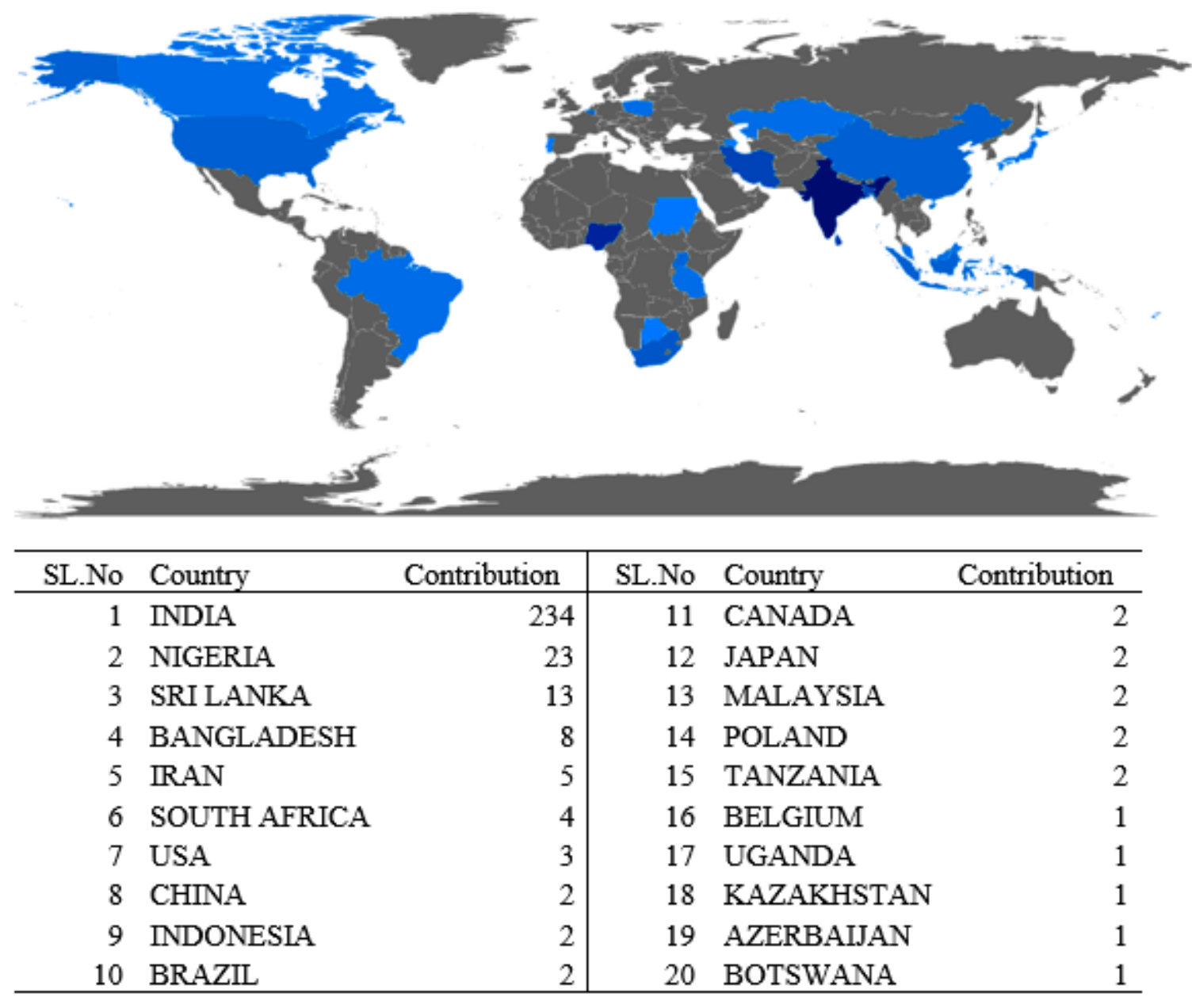

Figure 1

Scientific output by countries. 


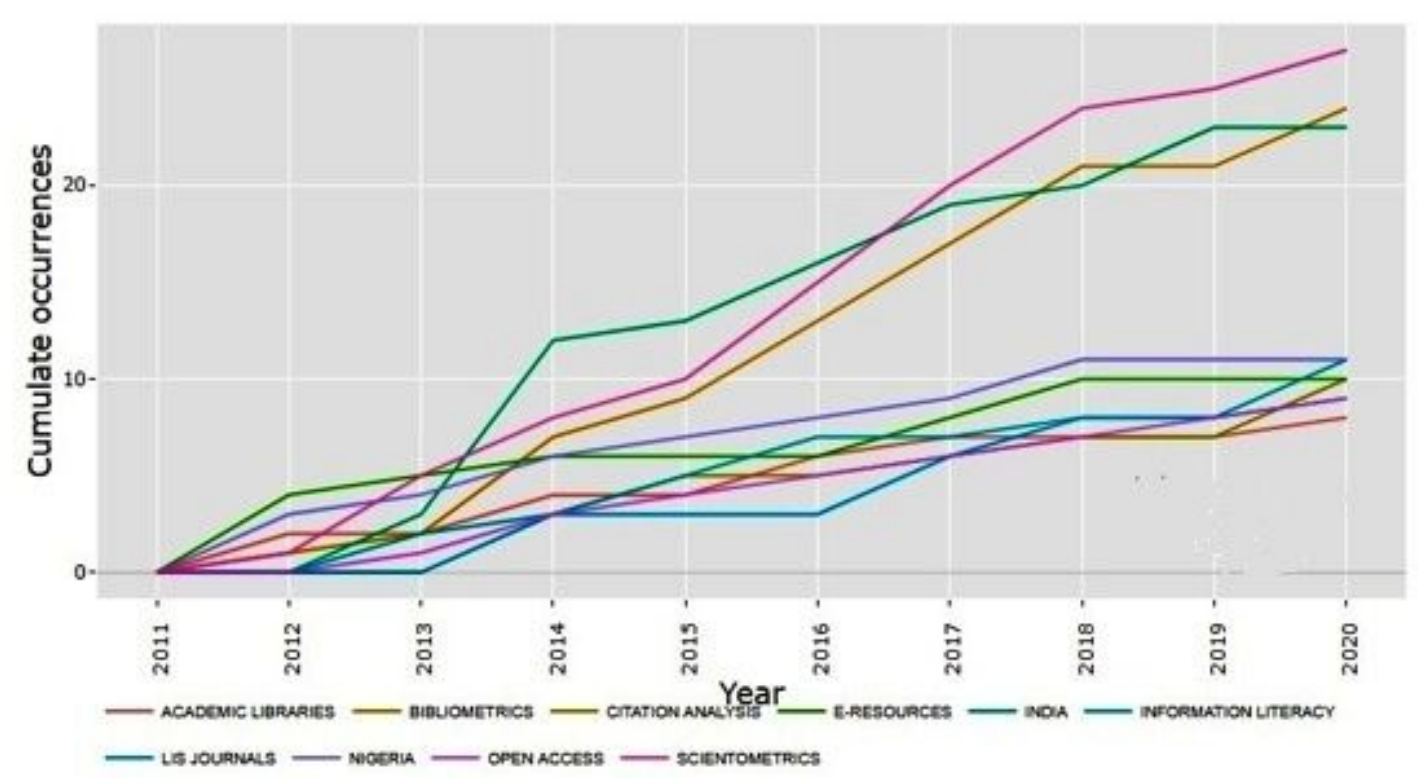

\begin{tabular}{lllllllllll}
\hline YEAR & SC & BI & IN & I & NI & CA & ER & LJ & OA & AL \\
\hline 2011 & 0 & 0 & 0 & 0 & 0 & 0 & 0 & 0 & 0 & 0 \\
2012 & 1 & 1 & 0 & 0 & 3 & 0 & 4 & 0 & 0 & 2 \\
2013 & 5 & 2 & 3 & 2 & 4 & 0 & 5 & 0 & 1 & 2 \\
2014 & 8 & 7 & 12 & 3 & 6 & 3 & 6 & 3 & 3 & 4 \\
2015 & 10 & 9 & 13 & 5 & 7 & 5 & 6 & 3 & 4 & 4 \\
2016 & 15 & 13 & 16 & 7 & 8 & 5 & 6 & 3 & 5 & 6 \\
2017 & 20 & 17 & 19 & 7 & 9 & 6 & 8 & 6 & 6 & 7 \\
2018 & 24 & 21 & 20 & 8 & 11 & 7 & 10 & 8 & 7 & 7 \\
2019 & 25 & 21 & 23 & 8 & 11 & 7 & 10 & 8 & 8 & 7 \\
2020 & 27 & 24 & 23 & 11 & 11 & 10 & 10 & 9 & 9 & 8 \\
\hline
\end{tabular}

Abbreviations: $\mathrm{SC}=$ Scientometrics; $\mathrm{BI}=$ Bibliometric; $\mathrm{IN}=$ India; $\mathbb{I L}=$ Information Literacy; $\mathrm{NI}=$ Nigeria; $\mathrm{CA}=$ Citation Analysis; $\mathrm{ER}=\mathrm{E}-$ Resource; $\mathrm{LJ}=\mathrm{Lis}$ Journals; $\mathrm{OA}=$ Open Access; $\mathrm{AL}=$ Academic Libraries

Figure 2

Dynamic Words Growth 
Conceptual Structure Map - method: MCA

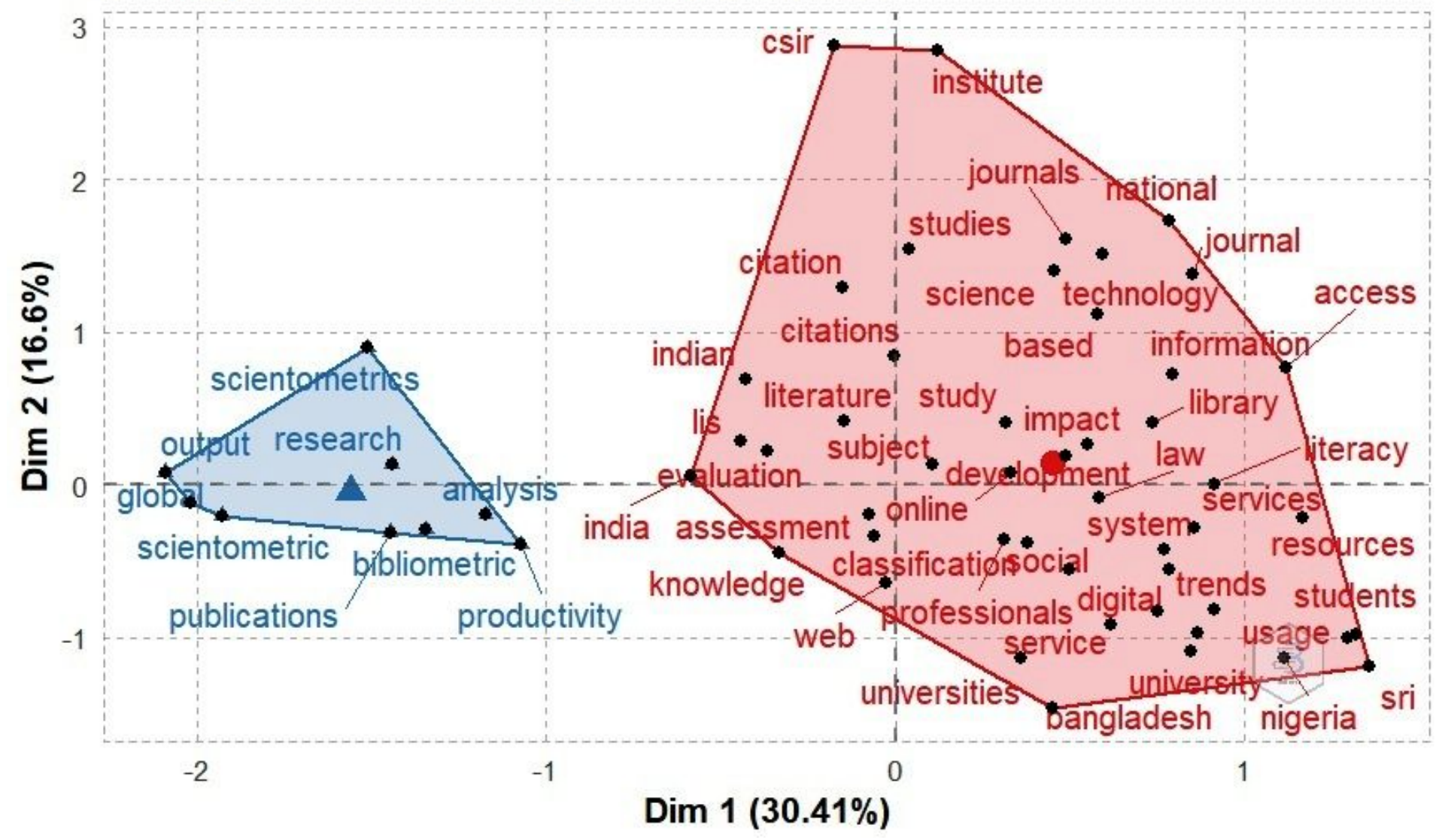

Figure 3

Factorial analysis of conceptual structure map-method: MCA of high-frequency titles 


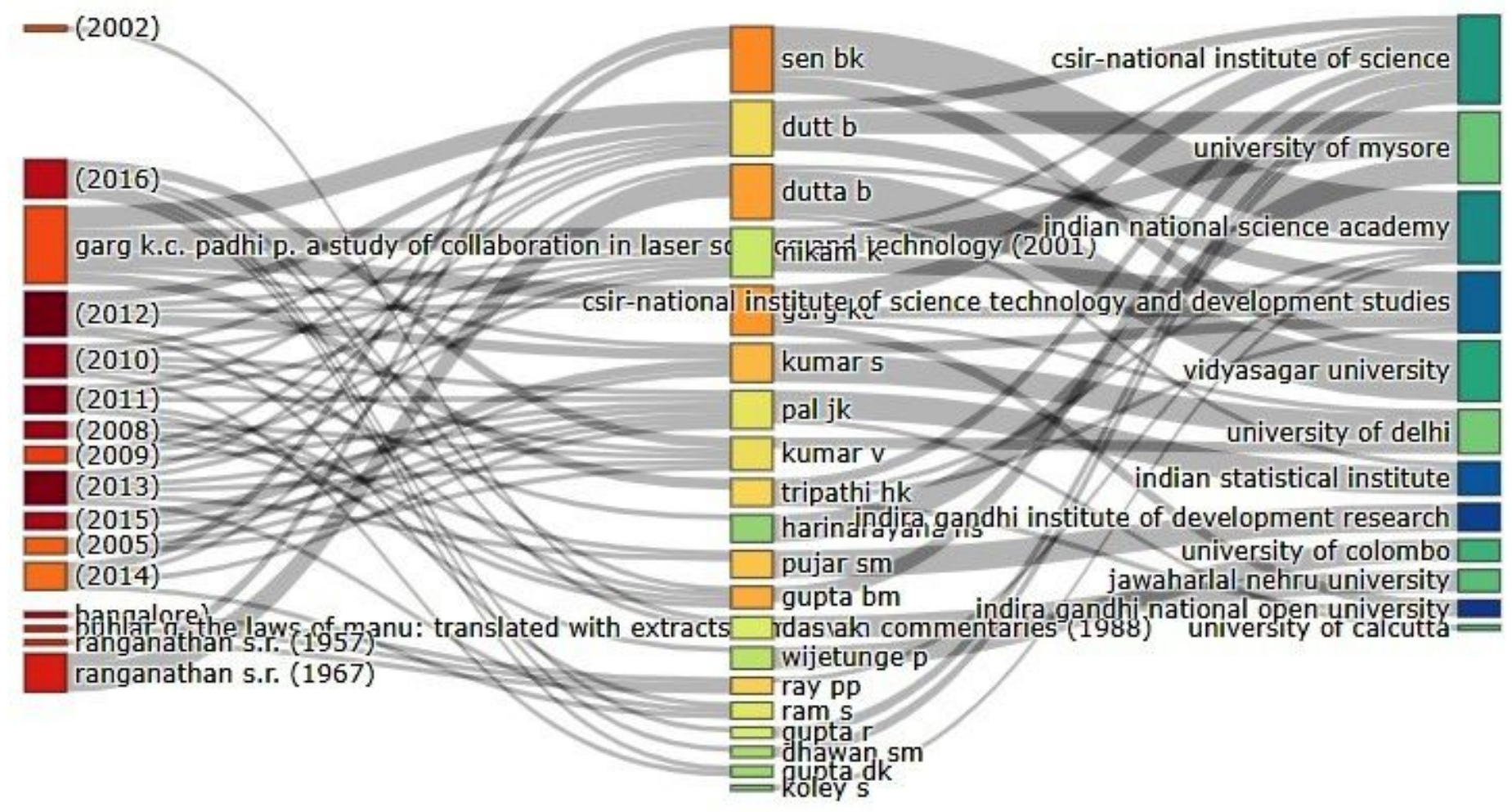

\section{Figure 4}

Three-fields plot relations between 20 (Authors-AFRICAN UNION, References-CR, Affiliations-AU_UN) A multi-field plot among authors, references, and author's affiliations in the top 20 rankings. 